\title{
SEXUAL DIMORPHISM IN BOSMINA: THE ROLE OF MORPHOLOGY, DRAG, AND SWIMMING
}

\author{
Hans Lord, ${ }^{1}$ RAgnar Lagergren, ${ }^{1,3}$ JAn-ERIK Svensson, ${ }^{2}$ AND NILs LundqvisT ${ }^{1,2}$ \\ ${ }^{1}$ Animal Ecology, Department of Zoology, University of Gothenburg, Box 463, SE-405 30 Göteborg, Sweden \\ ${ }^{2}$ University College of Borås, School of Engineering, SE-501 90 Borås, Sweden
}

\begin{abstract}
Some Bosmina water flea species develop morphological antipredatory defenses, such as long antennules and a high carapace, but in Bosmina (Eubosmina) coregoni gibbera these traits are larger and more variable in females than in males. Here we propose that this sexual dimorphism derives from differential costs of hydrodynamic drag and selection for mobility in males. We tested this hypothesis by estimating drag of several Bosmina morphologies by using scale models sinking in glycerin of different concentrations and viscosities. Body forms included males, sexual and asexual females of B. c. gibbera, and males and asexual females of Bosmina (Eubosmina) longispina, a taxon with less variable body shape. For a given body length or body volume, male models had lower drag than models of sexual and asexual females, suggesting that males can swim $14-28 \%$ faster with the same energy consumption. Consistent with this conclusion, video recordings showed that males of B. c. gibbera advanced 55-73\% farther than females in each swimming stroke. We conclude that hydrodynamic drag may have significant implications for swimming and evolution of sexual dimorphism in water fleas, and we suggest that males lack the defensive structures of females of B. c. gibbera (e.g., high carapaces) because competition over mates favors low drag.

Key words: Bosmina coregoni gibbera; Bosmina longispina; drag; hydrodynamic model; morphology; sexual dimorphism; swimming speed; zooplankton.
\end{abstract}

\section{INTRODUCTION}

Cladocerans are important models for how conspicuous morphological features are shaped by natural selection. For example, the external morphology of cladocerans is influenced both by genetic and environmental factors (Dodson 1989, Taylor and Hebert 1993). Among the latter group, responses to information chemicals derived from predators (kairomones) may be substantial in some species of Bosmina and Daphnia, where long spines and antennules, extreme carapace shapes, and crests may develop to help protect against predators (Tollrian and Dodson 1999, Lass and Spaak 2003). However, such long-featured morphs are often replaced by short-featured morphs when predation pressure declines (Kerfoot and Peterson 1980), indicating that these defenses are costly.

Previous studies have focused on morphological adaptations in parthenogenetic females to explain the adaptive significance of inducible changes in mor-

Manuscript received 19 January 2005; revised 17 August 2005; accepted 1 September 2005. Corresponding Editor:P. R. Leavitt.

${ }^{3}$ Corresponding author. E-mail ragnar.lagergren@zool.gu.se phology (Tollrian and Dodson 1999). However, sexual stages may differ from parthenogenetic females in many aspects of shape, leading to pronounced sexual dimorphism. In particular, male cladocerans are usually smaller than both sexual and asexual females, and do not develop as extreme body shapes and exuberant morphological structures (Gilbert and Williamson 1983, Lieder 1996, Benzie 2004). In addition, male zooplankton often swim faster than do females (Gerritsen 1980, Svensson 1997) possibly because of reduced hydrodynamic drag. Further, because male cladocerans likely compete over females, traits that decrease mating rate are selected against, including slow swimming speeds. Therefore, we propose that male cladocerans experience significant fitness trade-offs between increased protection associated with defensive structures and hydrodynamic effects of these structures on swimming performance.

Here we quantified morphological, behavioral, and hydrodynamic differences among sexes and reproductive stages of Bosmina (Eubosmina) coregoni gibbera Schoedler (see Plate 1) and Bosmina (Eubosmina) longispina Leydig. Asexual B. c. gibbera females exhibit a 
strong seasonal variation in morphology, with short-featured forms dominating in spring, whereas forms with long antennules and high carapaces dominate in summer and autumn. In contrast, the morphology of $B$. longispina is much less variable. Further, the males of both species have a low carapace, while $B$. $c$. gibbera males may have longer antennules than do male $B$. longispina. In addition, exposure to kairomones from the predatory cladoceran Leptodora kindti Focke can increase carapace height and length of the antennules in asexual B. c. gibbera females, thereby improving defense against raptorial predators (Hellsten et al. 1999, Lagergren and Stenson 2000). However, while both theoretical models and experiments suggest that high carapace increases hydrodynamic drag (Lagergren et al. 1997, 2000), little is known of how swimming performance varies as a function of reproductive dimorphism.

The main aim of this study was to test if males of $B$. c. gibbera experienced lower drag than did asexual and sexual females, and if so, whether this effect was manifested in altered swimming performances. We addressed these questions by combining hydrodynamic theory with empirical drag measurements using plastic models sinking in glycerin. From drag calculations, we predicted travel distance per swimming stroke, and compared that with actual travel distance using high-resolution video observation of individual B. c. gibbera.

\section{Methods \\ Estimating drag in relation to body shape}

Objects moving through a liquid are subject to drag, the magnitude of which depends on the speed, size, and shape of the moving object, and on the density and viscosity of the liquid. Due to the small size of Bosmina $(0.2-1 \mathrm{~mm})$, it is very difficult to measure drag of animals or models of natural size. However, for an object of a given shape, equality of Reynolds number (Re, an estimate of the relative importance of inertial and viscous forces) guarantees that the flow pattern around the object will be the same regardless of its absolute size (Vogel 1994). This hydrodynamic rule was used in this study to create realistic models of hydrodynamic drag of individual Bosmina.

Estimates of hydrodynamic drag were obtained from enlarged plastic models of Bosmina placed in fluids of varying viscosity. Viscous glycerin was diluted with water and used to vary $\mathrm{Re}$ within a range of values expected for Bosmina in natural environments. Change in viscosity also allowed us to correct for model size, as well as variations in travel velocity. In Bosmina longirostris travel velocities range from $\sim-1 \mathrm{~mm} / \mathrm{s}$ in the recovery stroke to $\sim 10 \mathrm{~mm} / \mathrm{s}$ in the power stroke (Zaret and Kerfoot 1980). Overall, Re values varied over the full range of values expected for Bosmina swimming in lakes.

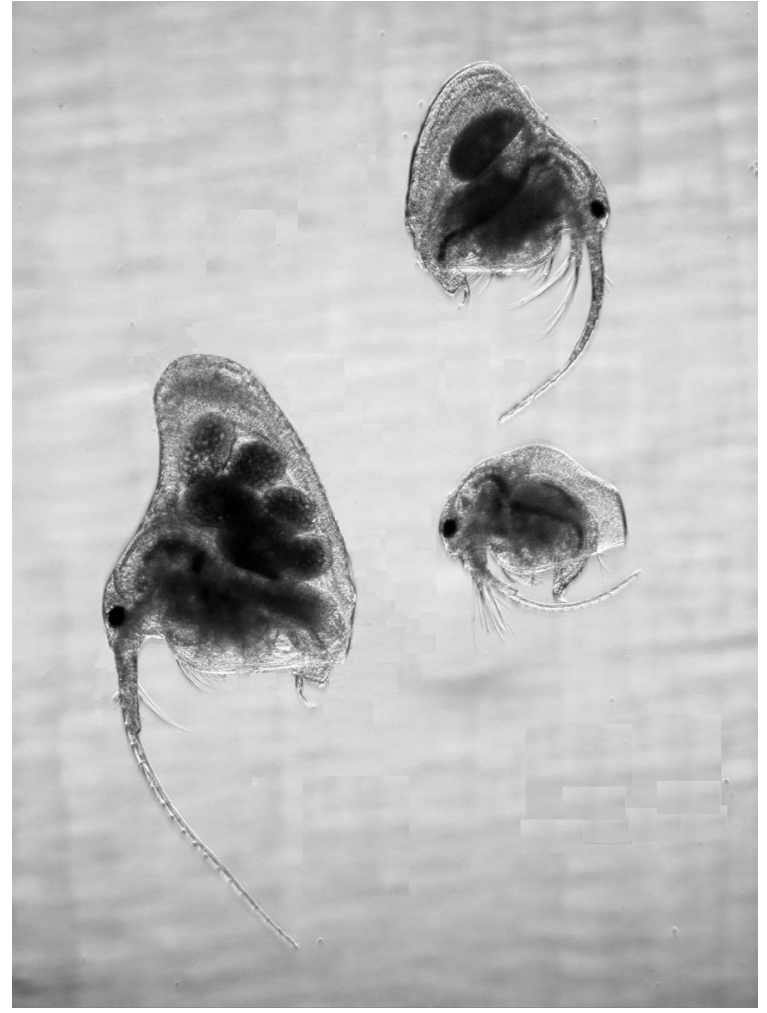

Plate. 1. The three reproductive categories of Bosmina (Eubosmina) coregoni gibbera. Males (lower right) are somewhat smaller and have shorter antennules and lower humps than sexual (top) and asexual (lower left) females. The individuals in the photo are ethanol preserved specimens from Lake Östersjön, southwest Sweden, 24 September 2002. The length of the male is $425 \mu \mathrm{m}$. Photo credit: J.-E. Svensson.

Seven Bosmina morphologies were used to develop plastic models, including field-caught males, parthenogenetic females (two forms) and sexual females of B. c. gibbera, laboratory-reared sexual females of $B$. c. gibbera, and male and parthenogenetic females of B. longispina obtained from the field (Fig.1; Appendix A). Original clones of all representatives were collected from Lake Östersjön in southwest Sweden $\left(57^{\circ} 93^{\prime} \mathrm{N}\right.$, $\left.12^{\circ} 70^{\prime} \mathrm{E}\right)$. Three-dimensional drawings of each morphotype were made using a dissecting microscope with a drawing tube, and were used to construct two gypsum models of each form scaled up $\sim 50$-fold. Consequent$1 \mathrm{y}$, the length of each model was $\sim 27 \mathrm{~mm}$. In addition, replicates $(a$ and $b$ ) of each model were constructed independently by two sculptors. These gypsum models were used to make silicone molds, from which the final experimental models were then cast in acrylate plastic. Pieces of salmon ribs were used to construct the antennules, although the experimental models lacked antennae. Models were balanced by adding lead inside the head region to provide correct mass and center of 

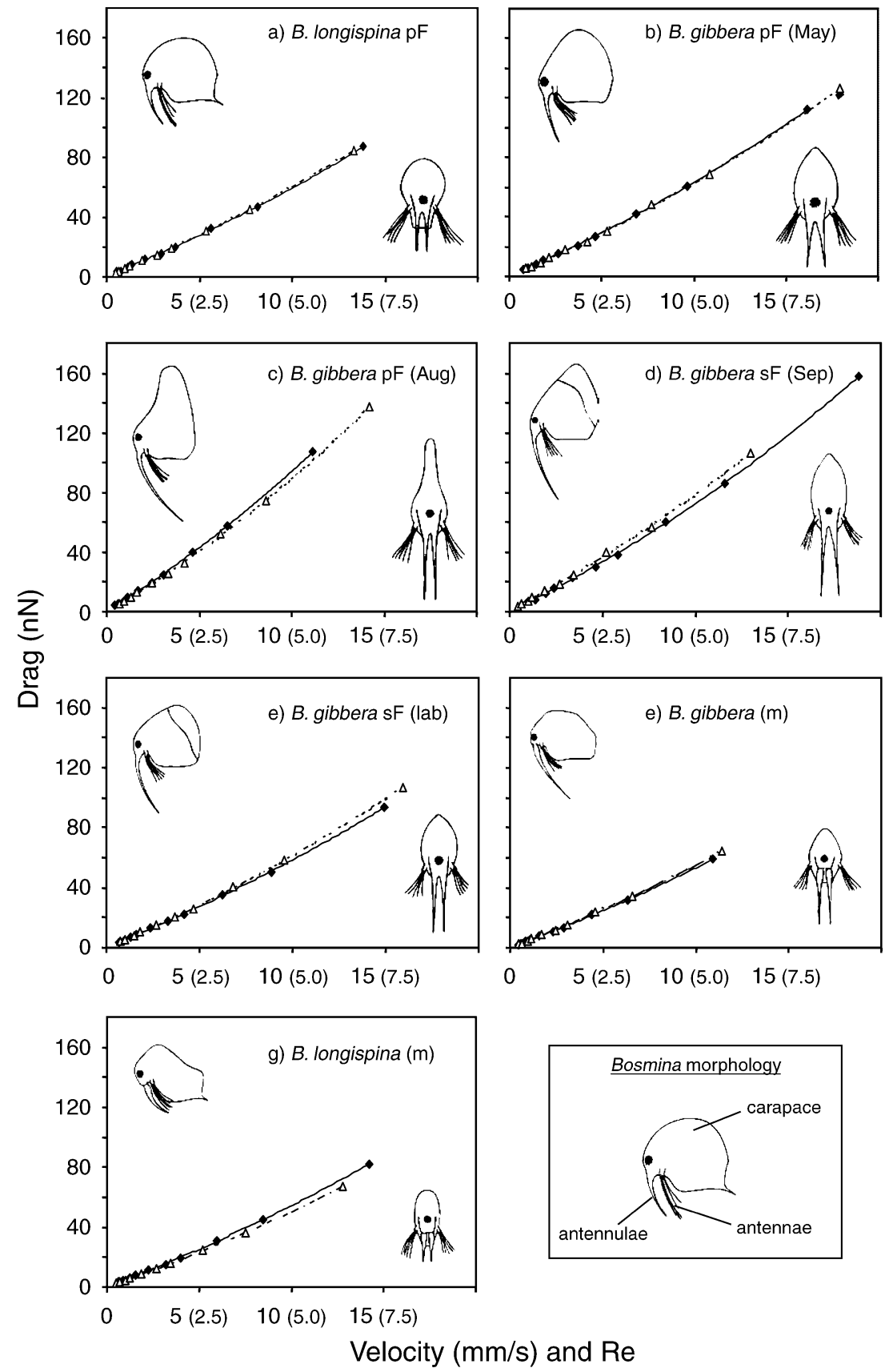

FIG. 1. Estimated drag ( $\mathrm{nN})$ vs. swimming speed (with Reynolds number scale, Re, in parentheses) at constant length $(0.5 \mathrm{~mm})$, calculated for Bosmina models scaled down to natural size swimming in $20^{\circ} \mathrm{C}$ water. Diamonds and triangles represent two replicates. The lines are polynomial regressions fitted to each replicate. General Bosmina morphology is shown in the lowest right panel. All plastic models lacked antennae. These models included (a) B. longispina parthenogenetic female (pF), (b) B. c. gibbera $\mathrm{pF}$ (May), (c) B. c. gibbera $\mathrm{pF}$ (August), (d) B. c. gibbera sexual female (sF) (September), (e) B. c. gibbera $\mathrm{sF}$ (lab), (f) B. c. gibbera male $(\mathrm{m})$, and (g) B. longispina $(\mathrm{m})$. 
gravity. As a result, models sank with steady speed, head first and without wobbling. Finally, model volume was calculated by estimating displacement volume in a known volume of water.

All hydrodynamic experiments were performed in an aquarium with a symmetrical octagonal shape with a distance of $40 \mathrm{~cm}$ between the parallel sides and filled with glycerin to a height of $37 \mathrm{~cm}$. The aquarium was large enough to avoid edge effects down to $\mathrm{Re}=0.2$ according to the method of Schlichting (1979). Ten different viscosities were tested for each model, starting with $99.5 \%$ glycerin. Thereafter viscosity was reduced by removing glycerin and adding water. In this way the dynamic viscosity was lowered successively from 0.99 to $0.22 \mathrm{~Pa}$. The water temperature varied between $21.4^{\circ}$ and $22.4^{\circ} \mathrm{C}$. Viscosity was determined with a Bohlin Rheometer VQR (Malvern Instruments, Malvern, UK).

For each hydrodynamic trial, a model was released head first just below the surface in the center of the aquarium and allowed to sink towards the bottom. Each fall was recorded with a video camera at 50 frames/s. Terminal velocity was measured within the interval from 20 to $30 \mathrm{~cm}$ below the surface, where neither acceleration nor retardation could be detected, and, therefore drag forces balanced gravity. Velocity of each model was estimated 10 times for each viscosity, and an average speed was calculated for estimation of drag.

\section{Bosmina drag}

The results of the plastic model experiment were used to calculate drag coefficients $\left(C_{\mathrm{dv}}\right)$ and to estimate drag for a Bosmina of natural size swimming in water at $20^{\circ} \mathrm{C}$. Details of these calculations are presented in Appendix B. The relationship between drag and observed terminal sinking velocity was estimated for each combination of plastic model and viscosity. From these plots, a seconddegree polynomial regression forced through origin of coordinates $\left(y=a x^{2}+b x\right)$ was fitted for each plastic model by least squares criteria. Regressions were estimated both for constant model volume and for constant model length. The drag of each model was also estimated relative (expressed as a percentage) to that of a parthenogenetic female $B$. longispina (model $1 \mathrm{a}$ ) for $20^{\circ} \mathrm{C}$ and three swimming speeds $(1,5,10 \mathrm{~mm} / \mathrm{s})$ using the equations from the polynomial regressions.

The equations derived from regression analysis were also used to theoretically estimate the distance traveled per swimming stroke as a function of energy expenditure per stroke, following the model of Lagergren et al. (2000). These theoretical calculations were then compared to the distance traveled per stroke as recorded by high-speed video observations of swimming B. c. gibbera. However, it should be noted that such calculations do not consider possible effects of interactions between the body and swimming appendages, and therefore may underestimate actual energy consumption.

\section{Video recordings of live animals}

Animals were collected from Lake Östersjön in late September 2002 with a plankton net (200- $\mu \mathrm{m}$ mesh). Sexual females, parthenogenetic females, and males of B. c. gibbera were isolated and placed in 250-mL Erlenmeyer flasks containing filtered $(25-\mu \mathrm{m}$ mesh) lake water. The swimming behavior of individual Bosmina was recorded in a low cylindrical plastic aquarium (16 $\times 5 \mathrm{~mm}$ ). A Redlake motionscope 1000 PCI digital high-speed camera (250 frames/s; DEL Imaging Systems, Cheshire, Connecticut, USA) and dissecting microscope $(8 \times$ magnification) were used to record swimming motions of individuals of each morphology during five 2-4 s sequences. The recordings started two days after field collection and were finished within three days. After the recordings, the specimens were preserved in Lugol's solution, and body length was measured using an inverted microscope $(125 \times)$.

Each recording was analyzed with Redlake software and a sequence of 13-77 frames was analyzed frame by frame. To avoid the underestimation of swimming speed that might arise because a three-dimensional technique was not used, a sequence was discarded if the animal moved out of focus. As a result, each animal was at least $1 \mathrm{~mm}$ from the closest wall, surface, or bottom. At that distance, wall effects could be ignored if $\operatorname{Re}$ was $>1.2$ (Schlichting 1979), and all animals analyzed reached maximum $\mathrm{Re}$ of at least 3.5. These data were then used to make graphs of cumulative distances traveled over time, from which the distance of individual swimming strokes was estimated.

\section{RESUlTs}

\section{Drop tests of plastic models}

The polynomial regressions revealed that terminal sinking velocity and drag were highly correlated $\left(r^{2} \geq\right.$ $0.998, P<0.001$ ) for constant-length comparisons and that the differences in drag between $a$ and $b$ replicates were small (Fig. 1). In general, drag increased more slowly with velocity of males than it did with females, although drag was greater for long-featured females than for those of comparable length but with short features. Further, in relative comparisons of equal body length, males had the lowest drag at all speeds (Fig. $2 a), \sim 9-15 \%$ less than that recorded for a parthenogenetic $B$. longispina female (model 1a). In contrast, the most long-featured forms of $B$. c. gibbera, i.e., the parthenogenetic (model 3) and the sexual (model 4) females, had the highest drag of all models, up to $55 \%$ and $31 \%$ greater than that of model $1 \mathrm{a}$, respectively. Similar patterns were recorded for all but the highest 


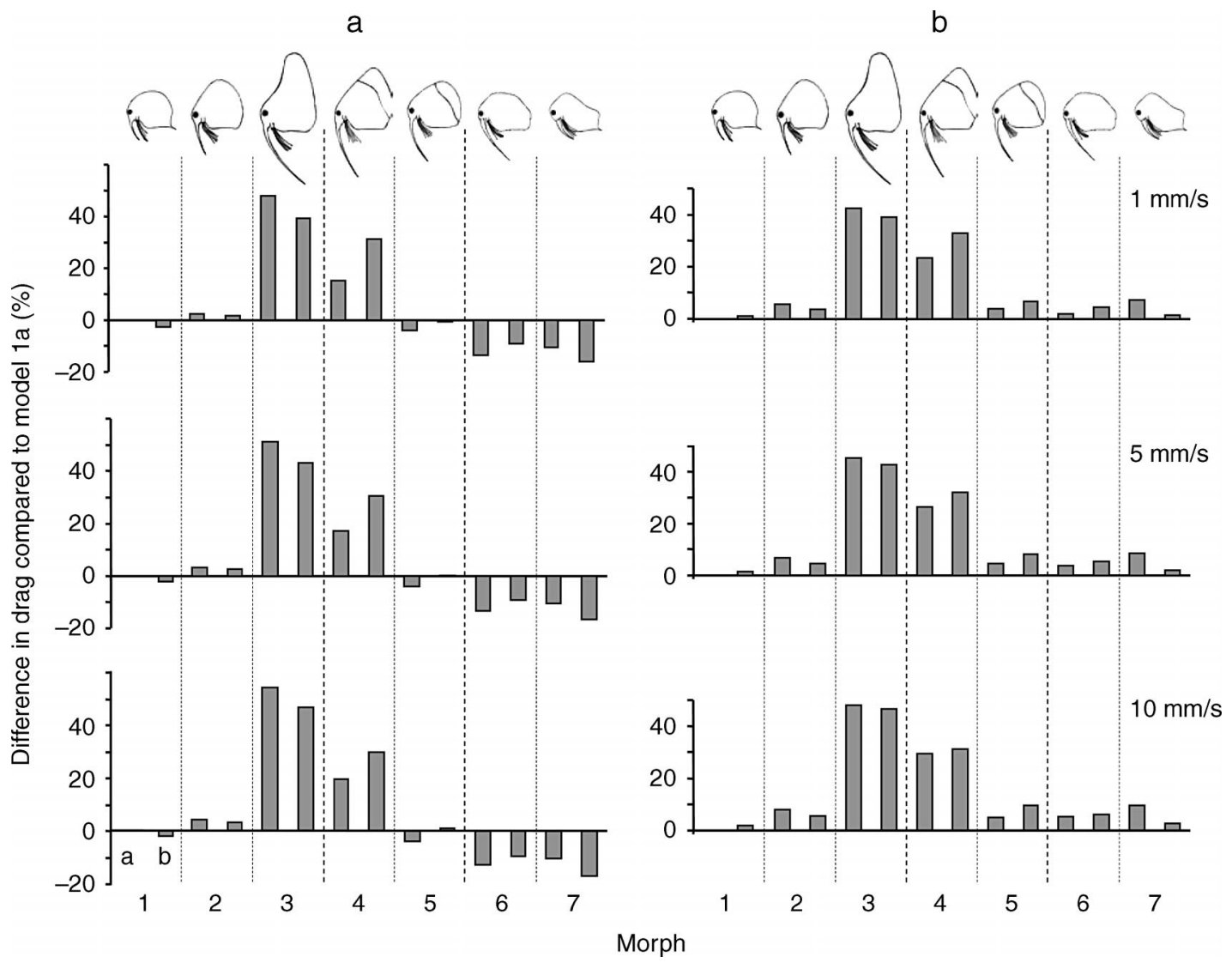

FIG. 2. Relative drag (\%), compared to the short-featured B. longispina morph (model 1a), for the 14 models (two replicates, $\mathrm{a}$ and $\mathrm{b}$, of seven morphs) used in the experiment. Comparisons were made at three swimming speeds: $1 \mathrm{~mm} / \mathrm{s}$, $5 \mathrm{~mm} / \mathrm{s}$, and $10 \mathrm{~mm} / \mathrm{s}$. (a) In the left panels all animals are mathematically scaled up or down to the same body length as model 1a when compared, but they may differ in volume. (b) In the right panels all animals are mathematically scaled up or down to the same volume as model 1a when compared, but they may differ in body length.

speed analyzed $(10 \mathrm{~mm} / \mathrm{s})$, in which differences among models were slightly larger than in other trials.

When comparisons were made assuming equal body volume (Fig. 2b), the differences in drag among morphologies were smaller, although the most long-featured forms of both parthenogenetic and sexual $B$. $c$. gibbera still had much higher drag than the other forms, respectively $39-48 \%$ and $24-33 \%$ compared to model 1a. In addition, both male forms had much lower drag than the most long-featured forms of B. c. gibbera sexual and parthenogenetic females $(19 \%$ and $27 \%$, respectively), somewhat higher drag than B. longispina parthenogenetic females (models $1 \mathrm{a}$ and $1 \mathrm{~b}$ ), and similar values to those of short-featured spring B. c. gibbera. Furthermore, in the constant-length comparisons, only model 4 displayed a noteworthy difference between $a$ and $b$ replicates (Fig. 2a), especially at the lowest swimming speed $(1 \mathrm{~mm} / \mathrm{s})$. In all other cases, the differences between replicates of the same model were small compared to the differences among models.
In all trials, drag coefficients $\left(C_{\mathrm{dv}}\right)$ were greater for models than for a true sphere (Appendix C). When used to theoretically estimate expected swimming performance, calculations with observed model $C_{\mathrm{dv}}$ suggested that B. c. gibbera should travel $\sim 28 \%$ farther per swimming stroke than would long-featured parthenogenetic females, and $18 \%$ farther than long-featured sexual females (Fig. 3a), assuming similar body length and the same energy expenditure per stroke. In comparison with equal model volume, calculations predicted that these differences were $21 \%$ and $14 \%$, respectively (Fig. 3b).

\section{Video recordings of live animals}

Measurements of actual swimming distance per stroke for live individuals confirmed that male $B$. gibbera traveled farther than did females for each swimming stroke (Fig. 4). Specifically, males traveled on average $55 \%$ farther per stroke than did parthenogenetic females and $73 \%$ farther than sexual females. Mean distance traveled per stroke $( \pm \mathrm{SD})$ was $176 \pm$ 


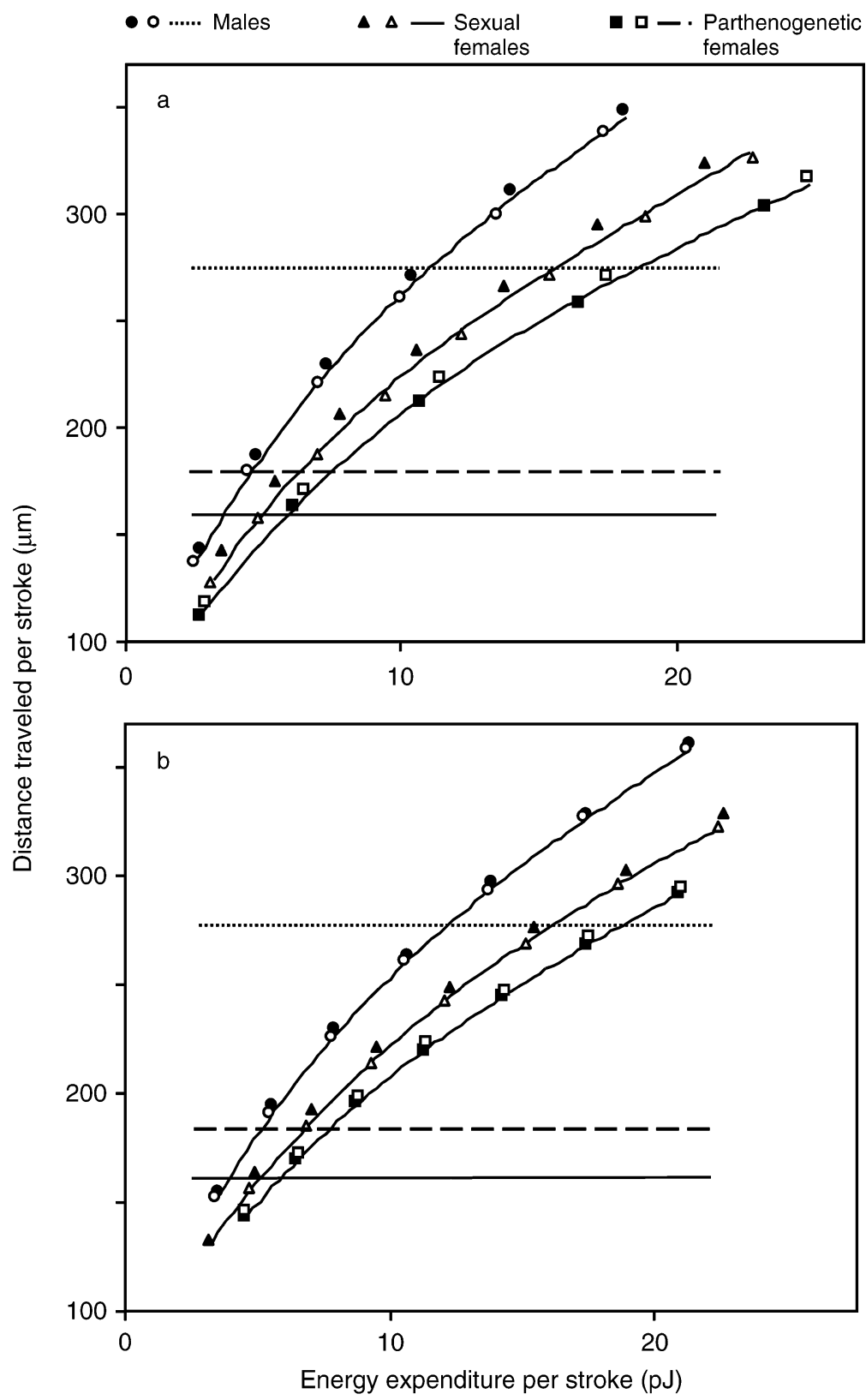

FIG. 3. Theoretic prediction of distance traveled per swimming stroke, as a function of assumed energy expenditure due to body drag and acceleration, calculated following Lagergren et al. (2000). Results are shown for males, sexual females, and parthenogenetic females of Bosmina c. gibbera for (a) equal-length and (b) equal-volume comparisons. Open and solid symbols represent the two replicates of each morph. Horizontal lines represent the mean distance traveled in the high-speed recordings, which are shown for comparison.

$34 \mu \mathrm{m}$ for parthenogenetic females $(n=15), 158 \pm$ $22 \mu \mathrm{m}$ for sexual females $(n=15)$, and $273 \pm 24 \mu \mathrm{m}$ for males $(n=14)$. In general, travel distance per stroke increased linearly with body length for both males $\left(r^{2}\right.$ $=0.40, P=0.019)$ and sexual females $\left(r^{2}=0.44, P\right.$ $=0.007$ ), but not for parthenogenetic females (Fig. 4).

\section{Discussion}

Analysis of the impact of morphological variation on the swimming performance of male and female Bosmina revealed that changes in carapace shape, normally induced by predatory invertebrates, altered hydrodynamic drag in such a way as to potentially impact mate 


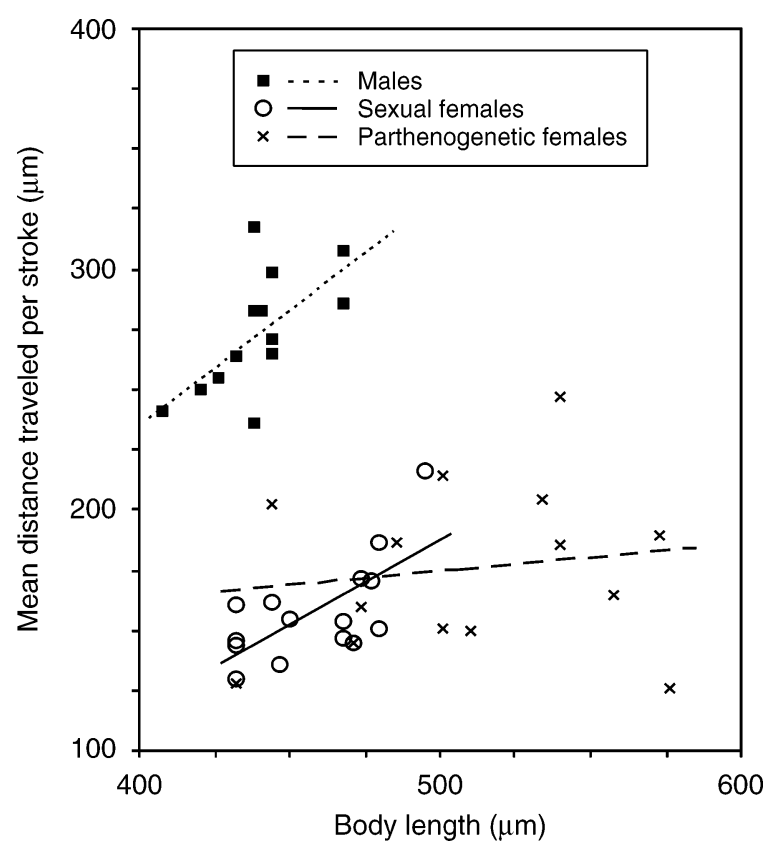

FIG. 4. Distance traveled per swimming stroke vs. body length, measured by high-resolution video analysis of $B$. $c$. gibbera. Each point represents the mean of 2-18 strokes analyzed.

selection. Overall, the morphology of Bosmina is probably a compromise reflecting opposing selective forces, which may differ between the sexes. Long-featured morphology may be favored by selection to reduced predation risk from grasping predators, such as predatory copepods and Leptodora kindtii (Kerfoot 1978, Hellsten et al. 1999). Further, the high drag associated with long-featured morphology may also increase encounter rate with food particles by making the velocity gradient around the animal steeper (Emlet and Strathman 1984). Since food level is positively correlated with clutch size (Wetzel 2001), elongated or enlarged features that increase drag may independently improve fitness. In contrast, our analyses suggest that shortfeatured morphology favors lower drag and higher swimming speed both to reduce search times for food (Tiselius et al. 1994) and to increase encounter rates with mates (Gerritsen 1980), particularly for males.

Accurate estimation of drag and energy expenditure of live zooplankton is difficult and usually requires simplifications of organismal shape or the hydrologic environment (Lehman 1977, Vogel 1994). For example, Bosmina has a rigid carapace and propels itself only by beating the antennae. As a consequence, thrust-producing structures cannot be separated from drag-inducing structures, such as is the case in hydrodynamic analysis of fish (Videler 1993). During the power stroke the antennae move close to the body opposite the swimming direction, and by viscous cross-flow transmission of momentum, this movement generates a counter-current effect. Although Bosmina antennae are folded towards the body to minimize their contribution to drag during the recovery stroke (Zaret and Kerfoot 1980), the antennae-body interaction may also increase total drag experienced at low Re (Vogel 1994). Therefore, because plastic models used here lacked filtering and moving swimming appendages, simulations of swimming speed probably underestimated true drag and energy consumption by Bosmina and should be interpreted mainly as a relative measure of morphological impacts on swimming performance. Fortunately, because our conclusions are based on comparisons among body forms, the overall conclusions of this study should not be compromised.

Different forms of Bosmina may experience different selective forces, each of which may alter the consequences of hydrodynamic drag on fitness. All bosminids live at low $\operatorname{Re}(<10)$ where flow is mainly laminar and surface area is of great importance for drag. Under these conditions, an almost spherical body shape is optimal to reduce drag related to body volume (Vogel 1994). However, experiments with plastic models revealed that Bosmina exhibit relatively high $C_{\mathrm{dv}}$ values compared to that of a sphere (Appendix C), suggesting that the effects of drag may be based on a different physical criterion (e.g., drag related to body length). Further, because drag calculations showed clear differences among the seven forms of Bosmina, it may be inferred that selective forces also differ among sexes and reproductive states. Because female clutch size depends on the volume of the brood chamber (Kerfoot 1974), natural selection may favor drag reduction on a volume basis, exemplified by the low drag for shortfeatured parthenogenetic females in the constant-volume comparison. In contrast, males may optimize drag on the basis of body length because swimming speed increases with body length. Consistent with this hypothesis, simulations revealed that the hydrodynamic drag of males was lower than that of all females, based on body length.

Morphological differences among male and female Bosmina likely result in substantial differences in energy requirements among sexes and reproductive states. For example, from Fig. 3, it can be calculated that a Bosmina with the morphology typical of longfeatured parthenogenetic females (model 3) will use $54 \%$ (equal-volume comparisons) to $69 \%$ (equal-length comparisons) more energy to swim as fast as males of an equivalent size. Similarly, sexual females (model 4) require $32 \%$ and $41 \%$ more energy, respectively, than do males. Such high energy costs to long-featured forms may help explain why males of B. c. gibbera do not adopt a morphology that is safer in the presence of raptorial predators. However, drag cannot be the sole 
factor explaining differences in swimming performance among sexes, as observed differences in stroke length between males and females (55-73\%) was much greater than theoretical expectations (14-28\%). In addition, males may differ from females in other respects such as energy usage per stroke, swimming efficiency, or relative development of locomotory organs and swimming muscles.

In conclusion, male and female Bosmina show clear differences in swimming capabilities associated with morphological structure and hydrodynamic drag. We suggest that males lack the defensive high carapace of females of B. c. gibbera, because competition for mates predominantly favors mobile individuals with low drag. Further, although it has been suggested that the small size of male Cladocera has evolved to increase swimming speed, we find instead that male velocity increases as a direct function of body size. Thus we suggest that bosminid morphology may be a gender-specific compromise between selection for low hydrodynamic drag and defense against invertebrate predators.

\section{ACKNOWLEDGMENTS}

We thank M. Andersson, S. Andersson, C. Askenmo, T. Bohlin, F. Götmark, J. Johnsson, J. A. E. Stenson, F. Sundström, D. Taylor, anonymous reviewers, and editor P. Leavitt, who offered helpful suggestions that greatly improved earlier versions of the manuscript. We also thank Susanna Edrud at SIK $\mathrm{AB}$ for assistance with viscosity measurements. The study was financially supported by grants from the Colliander and Willhelm and Martina Lundgrens science foundations and by grants from the University College of Borås (J-E. Svensson).

\section{Literature Cited}

Benzie, J. A. H. 2004. Cladocera: the genus Daphnia (including Daphniopsis). Kenobi Productions, Backhuys Publishers, Leiden, The Netherlands.

Dodson, S. I. 1989. Predator-induced reaction norms. BioScience 39:447-452.

Emlet, R. B., and R. R. Strathman. 1984. Gravity, drag and feeding currents of small zooplankton. Science 228:1016-1017.

Gerritsen, J. 1980. Sex and parthenogenesis in sparse populations. American Naturalist 115:718-742.

Gilbert, J. J., and C. E. Williamson. 1983. Sexual dimorphism in zooplankton (Copepoda, Cladocera, and Rotifiera). Annual Review of Ecology and Systematics 14:1-33.

Hellsten, M. E., R. Lagergren, and J. A. E. Stenson. 1999. Can extreme morphology in Bosmina reduce predation risk from Leptodora? An experimental test. Oecologia 118:23-28.
Kerfoot, W. C. 1974. Egg-size cycle of a cladoceran. Ecology 55:1259-1270.

Kerfoot, W. C. 1978. Combat between predatory copepods and their prey: Cyclops, Epischura and Bosmina. Limnology and Oceanography 23:1089-1102.

Kerfoot, W. C., and C. Peterson. 1980. Predatory copepods and Bosmina: replacement cycles and further influences of predation upon prey reproduction. Ecology 61:417-431.

Lagergren, R., M. Hellsten, and J. A. E. Stenson. 1997. Increased drag, and thus lower speed: a cost for morphological defence in Bosmina (Eubosmina) (Crustacea: Cladocera). Functional Ecology 11:484-488.

Lagergren, R., H. Lord, and J. A. E. Stenson. 2000. Influence of temperature on hydrodynamic costs of morphological defences in zooplankton: experiments on models of $\mathrm{Eu}$ bosmina (Cladocera). Functional Ecology 14:380-387.

Lagergren, R., and J. A. E. Stenson. 2000. Chemical cues from the invertebrate predator Leptodora kindtii affect the development of cyclomorphic traits in Eubosmina coregoni gibbera. Journal of Plankton Research 22:1213-1219.

Lass, S., and P. Spaak 2003. Chemically induced anti-predator defences in plankton: a review. Hydrobiologia 491: 221-239.

Lehman, J. T. 1977. On calculating drag characteristics for decelerating zooplankton. Limnology and Oceanography 22:170-172.

Lieder, U. 1996. Crustacea/Cladocera Bosminidae. Süsswasserfauna von Mitteleuropa. Band 8/Heft 2-3. Gustav Fischer, Stuttgart, Germany.

Schlichting, H. 1979. Boundary-layer theory. McGraw-Hill, New York, New York, USA.

Svensson, J.-E. 1997. Chaoborus predation and sex-specific mortality in a freshwater copepod. Limnology and Oceanography 42:572-577.

Taylor, D. J., and P. D. N. Hebert. 1993. Habitat-dependent hybrid parentage and differential introgression between neighbouringly sympatric Daphnia species. Proceedings of the National Academy of Sciences (USA) 90:7079-7083.

Tiselius, P., G. Nielsen, and T. G. Nielsen. 1994. Microscale patchiness of plankton within a sharp pycnocline. Journal of Plankton Research 16:543-554.

Tollrian, R., and S. I. Dodson. 1999. Inducible defenses in Cladocera: constraints, costs, and multipredator environments. Pages 177-202 in R. Tollrian and C. D. Harvell, editors. The ecology and evolution of inducible defenses. Princeton University Press, Princeton, New Jersey, USA.

Videler, J. J. 1993. Fish swimming. Chapman and Hall, London, UK.

Vogel, S. 1994. Life in moving fluids. Second edition. Princeton University Press, Princeton, New Jersey, USA.

Wetzel, R. G. 2001. Limnology: lake and river ecosystems. Third edition. Academic Press, San Diego, California, USA

Zaret, R. E., and W. C. Kerfoot. 1980. The shape and swimming technique of Bosmina longirostris. Limnology and Oceanography 25:126-133.

\section{APPENDIX A}

A table of body proportions of the Bosmina morphs used in the preparation of plastic models (Ecological Archives E087046-A1).

\section{APPENDIX B}

A description of how drag was calculated for Bosmina models (Ecological Archives E087-046-A2).

\section{APPENDIX C}

Figures showing drag coefficients vs. Reynolds number for the seven different forms of Bosmina (Ecological Archives E087-046-A3). 